\title{
GPPS-CH-2020-96
}

\section{Performance Analysis and Dynamic Simulation of Large-Scale Gas Turbine Combined Cycle Power System with Rapid Start-up and High Ramp Rate}

\author{
Yutaka Watanabe \\ Central Research Institute of Electric Power \\ Industry \\ yutaka@criepi.denken.or.jp \\ Yokosuka, Kanagawa, Japan
}

\author{
Toru Takahashi \\ Central Research Institute of Electric Power \\ Industry \\ toru-tak@criepi.denken.or.jp \\ Yokosuka, Kanagawa, Japan
}

\author{
Kojun Suzuki \\ Central Research Institute of Electric Power \\ Industry \\ s-kojun@criepi.denken.or.jp \\ Yokosuka, Kanagawa, Japan
}

\begin{abstract}
The use of renewable energy sources (REs) such as solar and wind power is necessary to reduce the global $\mathrm{CO}_{2}$ emissions. However, the fluctuating power output of REs renders the electric grid unstable, and thus, a realistic approach must be established to compensate for the load fluctuations associated with RE-based power generation. Gas turbine combined cycle power generation (GTCC) with a rapid start-up and high ramp rate is a potential solution to develop REbased power generation. Therefore, in this work, the conceptual design feasibility of such a system was examined in terms of both the thermal efficiency and operational characteristics. The development goals were as follows: a hot start-up time of approximately $10 \mathrm{~min}$, load following rate of approximately $20 \% / \mathrm{min}$, and thermal efficiency equal to or higher than that of the existing GTCCs. To attain these goals, first, the performance was analyzed to determine the optimal system configuration in terms of the thermal efficiency. Subsequently, a dynamic model was constructed using the Modelica-based tool developed by CRIEPI to demonstrate the operational potential of the proposed GTCC in the context of flexible startup operation.
\end{abstract}

\section{INTRODUCTION}

On the basis of the Paris Agreement of 2016, several countries agreed upon greenhouse gas emission reduction targets and to adopt measures to achieve them. In Japan, a national policy has been implemented to enable widespread use of renewable energy sources, such as solar and wind power, to considerably increase the contribution of renewable energy in the energy mix by 2030 and significantly reduce the amount of $\mathrm{CO}_{2}$ emissions by 2050 (METI, 2018; Government of Japan, 2019). The goal is to reduce, by 2050 , the amount of greenhouse gases by $80 \%$ compared to the level in FY2013. In particular, in the Fifth Strategic Energy Plan passed by the Japanese Cabinet in July 2018, renewable energy was defined as the main power supply, and a plan was outlined to increase its contribution to Japan's energy mix from $22 \%$ to $24 \%$ by 2030.

However, renewable energy sources are fundamentally unstable power sources whose output is considerably affected by the weather conditions, and it is necessary to establish countermeasures against load fluctuations to ensure the stable operation of the power systems. At present, pumped-storage power generation and thermal power generation with a high flexibility are used to overcome the aforementioned limitations; however, further countermeasures against load fluctuations are required in preparation for the mass introduction of renewable power sources. To this end, researchers are attempting to improve the technologies to predict the output of renewable energy sources and develop power storage technologies such as storage batteries. However, several issues still remain; for instance, the accuracy of prediction of the output must be improved, cost of development of power storage technologies must be reduced, the loss in power charging and 
discharging must be reduced, and the capacity must be enhanced. In electric power systems, it is necessary to stabilize the electric power as well as the associated frequencies and voltages. In this regard, synchronous generators, such as those used in thermal power generation are indispensable power sources. Moreover, power can be generated in this manner at any time as long as fuel is supplied, and thus, thermal power generation is key to maintain a high quality and stable supply of power. In the future, it is expected that the adoption of countermeasures against load fluctuations in thermal power generation will become more critical, and thermal power plants will be required to operate at partial loads that involve frequent start-stop operations and abrupt load fluctuations. Such a scenario involves concerns regarding a decrease in the thermal efficiency and increased $\mathrm{CO}_{2}$ emissions from single thermal power units. Thus, it is a challenge to realize both the stable operation of the system and a reduction in the $\mathrm{CO}_{2}$ emissions. Among thermal power sources, gas turbine combined cycle power plants (GTCC) that use LNG as the fuel exhibit excellent flexibility and are highly efficient and clean. If the flexibility of such systems can be further improved in terms of the start-up time and the changes in the output rate, and a power supply that can operate with a high efficiency in a wide range of loads can be developed, GTCC plants can represent a promising practical solution to address the aforementioned load fluctuation problems (Hermans et al., 2018; IEA, 2018).

In FY2018, Mitsubishi Heavy Industries Ltd. and the Central Research Institute of Electric Power Industry (CRIEPI), supported by the New Energy and Industrial Technology Development Organization (NEDO), initiated a research project to develop an advanced GTCC. In particular, this project is aimed at developing elemental technologies (combustion, control, aerodynamics, materials, etc.) to build a flexible advanced GTCC, with a reduced start-up time, improved ramp rate, lower minimal output, and high efficiency in the partial load band, as indicated in Fig. 1 and Table 1. Moreover, the feasibility of this system for application to an actual plant is expected to be examined. In this project, the contribution of CRIEPI is to conduct the performance analyses of the system to clarify the conditions and necessary approaches to achieve the target thermal efficiency, and to evaluate the operational ability of the GTCC by analyzing the dynamic characteristics, especially those pertaining to a steam bottoming cycle including a heat recovery steam generator (HRSG) and steam turbine (ST). To this end, a model-based approach is adopted, in which a simplified simulation model of a target GTCC is used to predict the performance levels and the influence of material thermal stress and fatigue life consumption in an HRSG.

In this work, the potential performance characteristics were preliminarily evaluated in terms of the thermodynamic performance and operational flexibility of an advanced GTCC system. First, the realistic target GTCC system configuration was examined by performing heat and mass balance calculations under certain constraints. Next, a dynamic model of the target GTCC was developed to investigate the basic operational performance capacity of the power output, assuming the installation of a high flexibility GT. Using the developed model, the impact of the start-up behavior of the steam bottoming system and the possibility of reducing the start-up time were evaluated. It should be noted that we are considering evaluating the maximum effects on materials using the results of dynamic analysis as the next step and start-up sequence is kept simple and some actual mechanical limitations such as the thermal stress limit imposed by the turbine rotor and heat transfer tube are neglected.

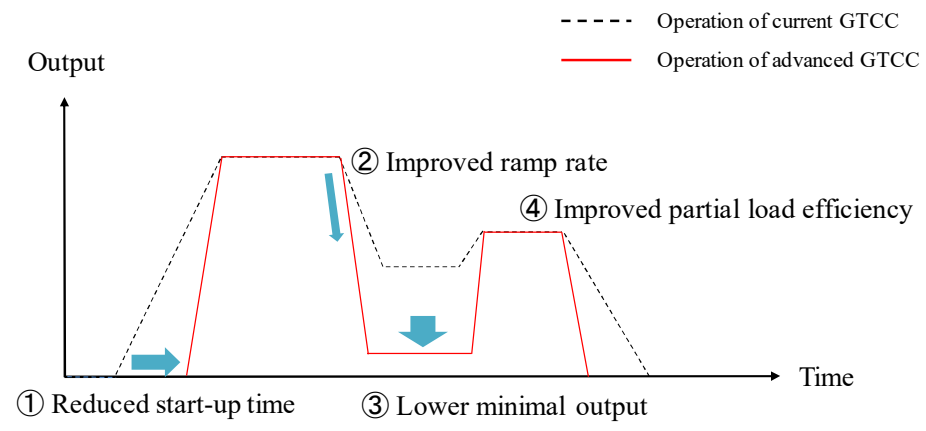

Figure 1 Concept of performance improvement of the existing GTCC

Table 1 Development goals of GTCC

\begin{tabular}{|c|l|l|l|l|}
\hline No. & Items & Target performance & Main effects \\
\hline 1 & Reduced start-up time & $\begin{array}{l}10 \mathrm{~min} \text { (hot start, GT start-up } \sim \text { full } \\
\text { load) }\end{array}$ & $\begin{array}{l}\text { Respond to the loss of the forecasted } \\
\text { power generated by the PV }\end{array}$ & $\begin{array}{l}\text { Eliminate of supply and demand } \\
\text { imbalance }\end{array}$ \\
\hline 2 & Increase load following rate & $20 \% / \mathrm{min}$ & Expand the acceptance of the PV \\
\hline 3 & Reduce minimum load & $10 \%$ (Single shaft GTCC) & $45 \%$ \\
\hline 4 & $\begin{array}{l}\text { Increase part-load thermal } \\
\text { efficiency }\end{array}$ & $\begin{array}{l}\text { Rated efficiency minus } 10 \% \text { at half } \\
\text { load (relative value) }\end{array}$ & $\begin{array}{l}\text { Reduce fuel consumption and } \mathrm{CO}_{2} \\
\text { emissions }\end{array}$ \\
\hline
\end{tabular}




\section{SYSTEM CONFIGURATION AND PERFORMANCE ANALYSIS}

\section{Target system of GTCC}

This section describes the investigation of a realistic target GTCC system configuration by performing heat and mass balance calculations under certain constraints.

The target GTCC is composed of a GT, a HRSG and a ST, which are widely used as the steam system of the current commercial GTCCs. The HRSG is a triple pressure and reheat type system having a natural circulation evaporator path in the high-pressure, intermediate-pressure, and low-pressure (LP) circuits. The ST has a high-pressure turbine (HPT), intermediate-pressure turbine (IPT) and low-pressure turbine (LPT). As a high-efficiency GT that can be expected to be introduced to the market in the near future, a $1650{ }^{\circ} \mathrm{C}$ class GT is assumed. The target thermodynamic efficiency is set to approximately $63 \%$ lower heating value. The system configuration and specifications for each equipment of the steam system for bottoming and the $1650^{\circ} \mathrm{C}$ class GT as the topping system are derived from the GTW Handbook $(\mathrm{GTW}, 2019)$. The constraints of the steam system in the heat and mass balance analysis are as follows.

- The main steam and reheat steam temperatures are less than $600{ }^{\circ} \mathrm{C}$

- The approach point temperature difference for each heat exchanger is more than $2{ }^{\circ} \mathrm{C}$

- The pinch point temperature difference for each heat exchanger is more than $5{ }^{\circ} \mathrm{C}$

- The HRSG outlet gas temperature is more than $85^{\circ} \mathrm{C}$

- The LPT outlet quality is more than 0.9

- The air conditions are as follows: Temperature $=15{ }^{\circ} \mathrm{C}$, Pressure $=0.1013 \mathrm{MPa}$, Humidity $=60 \%$

- LNG is used as fuel

- The condenser pressure is constant at $0.005 \mathrm{MPa}$

- Heat and mechanical losses are neglected

The system configuration and steam conditions that could achieve the target thermodynamic efficiency were investigated under the aforementioned conditions. The heat and mass balance calculation was performed using the EnergyWin software (Koda, E. and Takahashi, T. 2002), which can promptly evaluate various types of thermodynamic systems, based on the energy and mass balance (Takahashi et al. 2007; Takahashi et al. 2011).

\section{Results of the performance analysis}

The calculation results for the system configuration and heat mass balance at the rated power output are shown in Fig. 2. The GT pressure ratio was 23 , and the main steam / reheat steam temperature was $600{ }^{\circ} \mathrm{C}$ at the rated power output. To determine the partial load efficiency, various conditions under which the relative efficiency under the $50 \%$ load and the thermodynamic efficiency at the rated output were within minus $10 \%$ were examined. At the $50 \%$ load, the main steam / reheat steam temperature could be maintained at $600{ }^{\circ} \mathrm{C}$ by setting the combustor outlet temperature as $1480{ }^{\circ} \mathrm{C}$, the combustor pressure ratio to approximately 13 , and the GT outlet gas temperature to $655^{\circ} \mathrm{C}$, which could ensure that the thermodynamic efficiency was higher than that of the existing GTCC. The IGV and fuel flow rate are controlled to maintain the TOT at $655^{\circ} \mathrm{C}$. Under partial load, the temperature was within the allowable range of the rated load, but the thermal stress may have increased. For this purpose, material tests are being planned in addition to the quantitative evaluation by thermal stress analysis using simulations.

In this case, the adiabatic efficiency of each rotating equipment was not considerably different from that of the current equipment, and the target thermodynamic efficiency could be obtained under the device specifications expected to be readily available in the near future. These results were used to analyze the dynamic characteristics analysis, as described in the subsequent sections.

\section{ANALYSIS OF DYNAMIC CHARACTERISTICS OF START-UP PROCESS}

\section{Dynamic model of GTCC}

This section describes the development of a dynamic characteristic analysis model based on the system whose plan performance was examined as described in the previous section. The start-up characteristics were examined in terms of the operability.

In general, dynamic models of the GTCC plant can help understand the transient behaviour during the start-up and load following operations (Alobaid et al., 2017). Physical modeling is especially effective in predicting both the dynamic behaviour and steady-state conditions over the entire operational range of a plant. Such a model can be applied to not only existing plants but also new conceptual plants if the appropriate equipment information is available. 

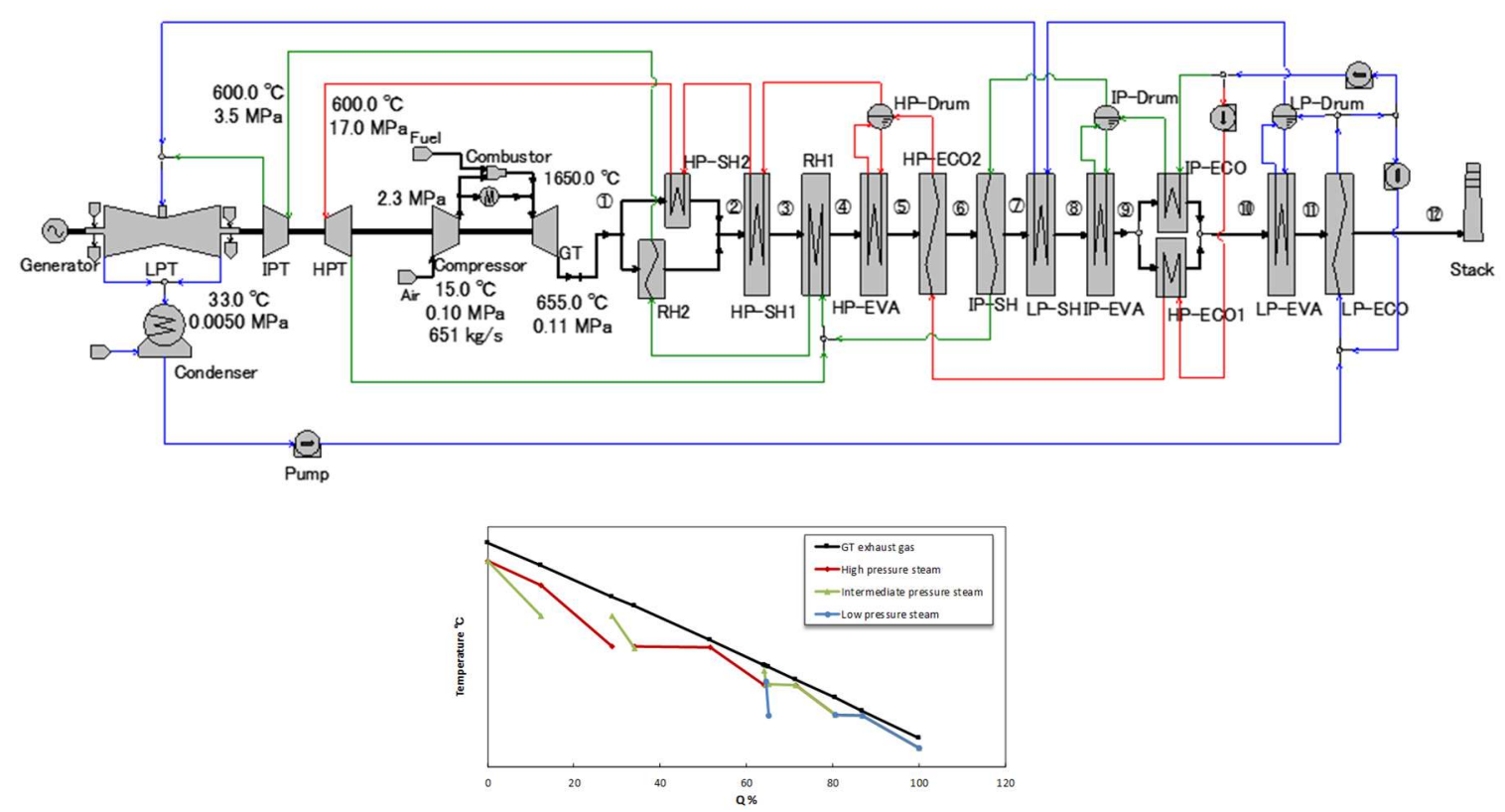

Figure 2 System configuration of the target GTCC

In this study, the Modelica tool developed by CRIEPI to evaluate the dynamic characteristics of new or existing thermal power generation systems (Watanabe et al., 2017; Watanabe and Traverso, 2019) was used to construct the dynamic model of an advance GTCC. The CRIEPI simulation tool includes various component models that can be used to analyze the dynamic characteristics of thermal power systems, such as those of a compressor, gas turbine, heat exchanger, and steam drum; nodes to calculate the pressure and enthalpy between components; valves to calculate the flow parameters; and control models such as a PI controller. These component models are mainly based on the mass and energy conservation equations, and the thermodynamic properties of water/steam and gas can be calculated. The component models are stored in packages, thereby facilitating the construction of a complex dynamic system model by using the relevant component models.

The dynamic model consisted of the equipment model and the control system model, as shown in Fig. 3. The GT model was simplified and the temperature and flow rate of the GT exhaust gas side were set as the input boundary conditions and the pressure drop of the GT exhaust gas side was neglected in this model. The HRSG and ST model were developed with reference to the heat mass balance results discussed previously. The heat exchanger models used in HRSGs are finite volume models considering mass and energy balance equations for each volume for both the gas and water/steam side. The effect of metal heat conduction is also considered for the heat transfer. The pressure drop of the GT exhaust gas side was neglected in this model. The ST model calculates the flow rate from the differential pressure as well as the power output using the adiabatic efficiency. The performance parameters of each equipment were calibrated using the abovementioned heat and mass balance data. The main control of the HRSG and ST system included the ST control valve control, turbine bypass control, drum water level control, steam temperature control, and LP economizer recirculation control. In terms of the ST control valve, the steam generated by the HRSG changed according to the GT output (GT outlet gas temperature and flow rate), and a time delay was present until the steam stabilized. Therefore, the control valve did not have a governor function and was fully open during normal operation. During start-up, the opening size was increased systematically in coordination with the turbine bypass control as the steam flow increased owing to the increase in the GT output. The turbine bypass controller adjusted the bypass valve opening to collect the excess steam in the condenser during start-up and stop operations. The drum water level controller controlled the steam flow rate by adjusting the feedwater flow rate and maintaining the water level at a constant value. The high pressure and reheated steam temperature were controlled using the attemperator, which maintains the degree of superheat under the limit value by spraying water into the steam line. The LP economizer recirculation controller was used to change the inlet water temperature of the LP economizer by extracting water from the outlet of the LP economizer. The geometries of each heat exchanger in the HRSG and pipes between the HRSG and ST, in terms of the volume and heat capacity parameters, were considered based on the design data of the plant, as estimated using the commercial software GTPRO developed by Thermoflow (Thermoflow, 2020). A model of the plant with the considered configuration was established in GTPRO, and the volume and heat capacity of each heat transfer tube of the HRSG and pipes between the HRSG and ST were set based on the equipment specifications determined previously. The characteristics of the developed virtual plant model were thus similar to those in actual operational conditions. 


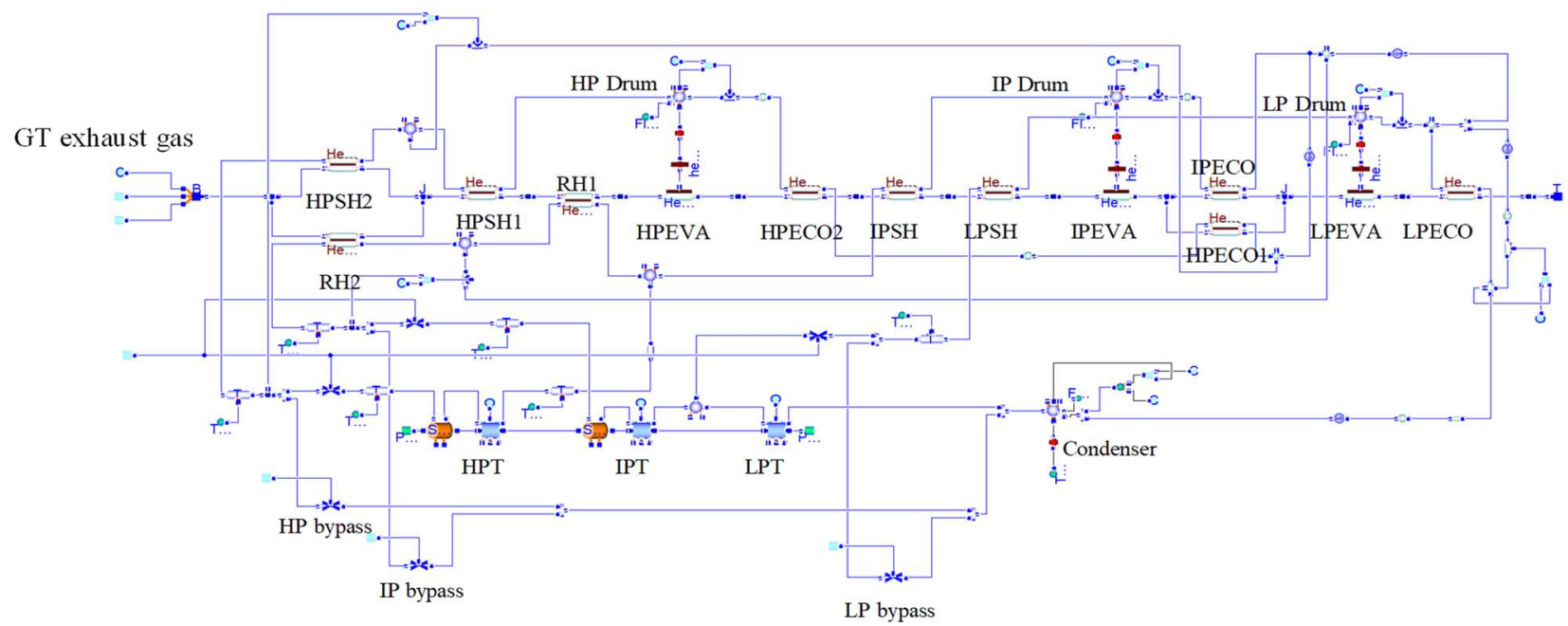

Figure 3 Overview of dynamic model of GTCC

\section{Start-up simulation conditions}

As a preliminary study, the potential of reducing the start-up time when employing a high flexibility GT was examined. The rapid start-up process was set as shown in Fig. 4. It was assumed that the GT reached the rated rotating speed in 5 min and the rated output in $2 \mathrm{~min}$ (at a GT load change rate of 50\%/min). The steam control valves of the ST were open and the bypass valves were closed in $2 \mathrm{~min}$ when the steam temperature reaches the ventilated steam condition. The start-up characteristics of the ST were examined by considering the conditions of the change in the gas temperature and flow rate at the GT outlet. The initial conditions for the start-up of the steam system corresponded to those of a hot start. Because the objective of this work was to understand the critical characteristics of the equipment, the constraints of thermal stress on the thick part of the HRSG/ST were not considered. Moreover, because all the constraints in practical operation were not considered, the actual machine does not necessarily undergo a similar operation.

To enhance the operability of the steam bottoming system, a duct burner was installed in the GT exhaust gas duct, as the use of a duct burner has been noted to improve the flexibility of power systems (Alobaid, 2018; Caceres et al., 2018; Liese and Zitney, 2018). A duct burner is generally used to increase the ST power output; however, such burners can potentially enhance the start-up and load change processes, such as pre-warming. Figure 5 shows the schematic of the GTCC system with a duct burner. Figure 6 shows the start-up process of the GT and duct burner. As shown in Fig. 6, the GT exhaust gas temperature was assumed to be increased to the rated GT exhaust gas temperature by the duct burner from the time that the GT was started up.

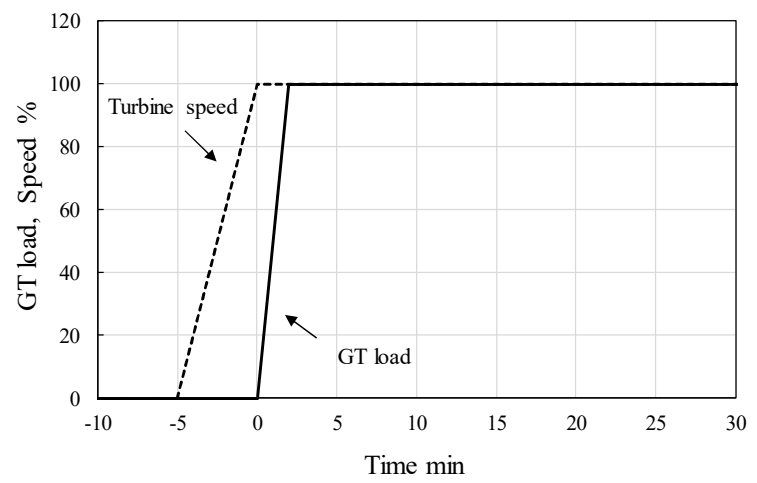

(a) Start-up process of GT



(b) GT exhaust gas temperature and mass flow

Figure 4 GT calculation condition (normal) 


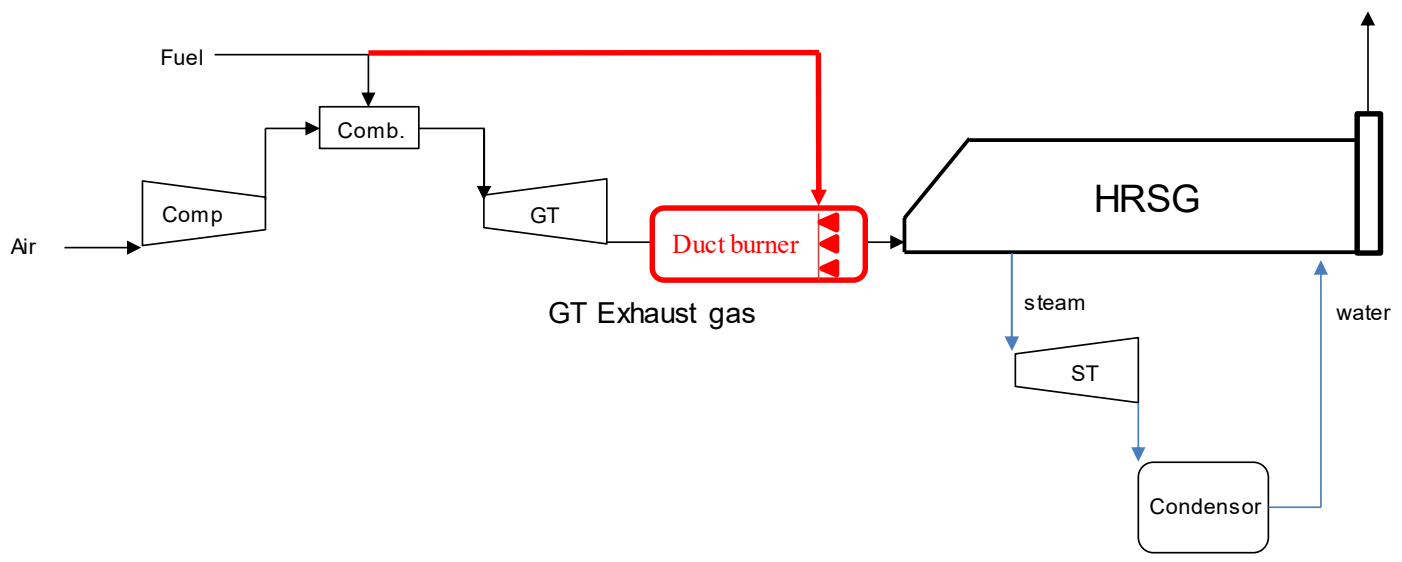

Figure 5 Concept of adding duct firing system

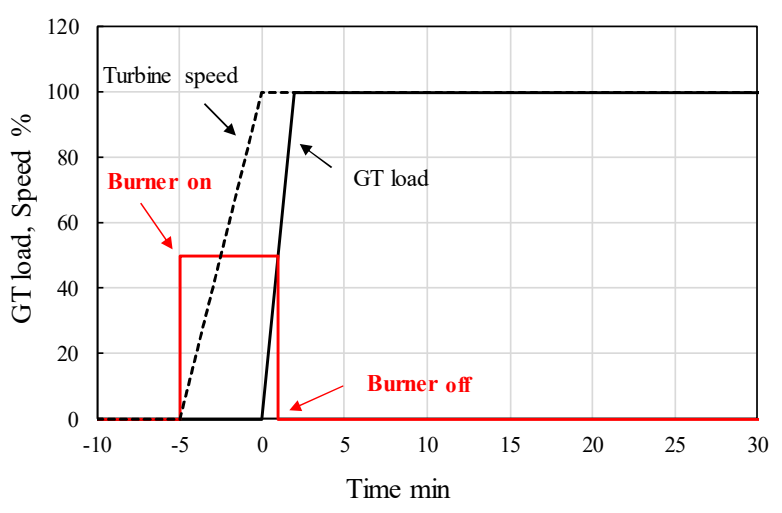

(a) Start-up process

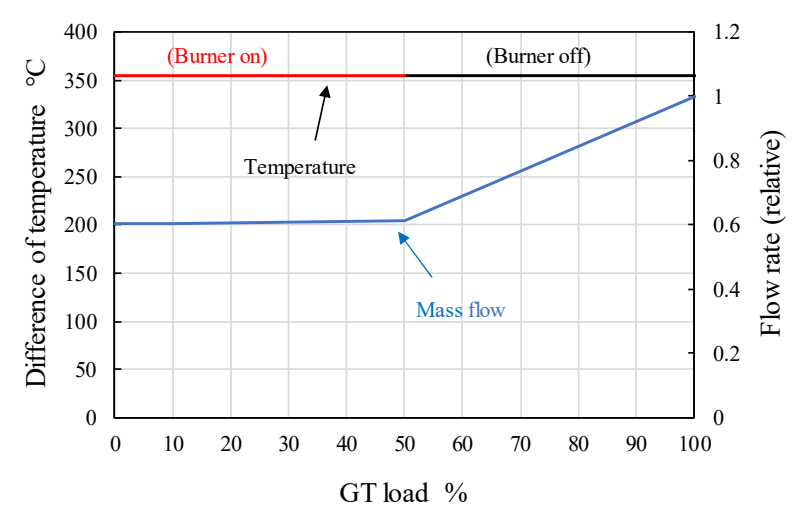

(b) GT exhaust gas temperature and mass flow

Figure 6 Simulation conditions (with duct firing)

\section{Simulation result}

Figures 7 and 8 show the simulation result for the system without and with a duct burner, respectively. In both the figures, subfigures (a) show the ST power output, and (b) and (c) show the inlet steam conditions of the HPT and IPT respectively. Figure 7 shows that the ST power output did not reach the rated power output in the target time, that is, $5 \mathrm{~min}$. The steam temperature became $600{ }^{\circ} \mathrm{C}$ in approximately $5 \mathrm{~min}$, and the pressure and flow rate changed gradually owing to the heat capacity and volume of the HRSG. The ST power output did not reach the output demand in 5 min even when various mechanical constraints in practical operation such as a thermal stress and a life consumption were neglected.

Figure 8(a) shows that the ST output speed was increased, and the target 5 min start time was approached. This is because by using a duct burner, the amount and temperature of steam can be increased before the GT output is increased. It was effective in improving the rise characteristics as shown in Figs. 8 (b) and (c). This result indicates that increasing the GT exhaust gas temperature at a low load can improve the starting characteristics of the steam bottoming system. On the other hand, the rate of increase of the gas temperature from the middle of the load increase was not significantly affected and the temperature rise rate of the steam was faster. It indicates the possibility of greater effects of thermal stress on the components. As shown in Fig. 8(d), the start timing of the Super Heater (SH) spray was quicker and the flow rate tended to increase, owing to the rapid temperature change. These are issues related to the increased capacity of the temperature reducer and increased thermal stress of the material. Therefore, in order to improve the flexibility, it may be necessary to further increase the temperature rise with duct burners, to improve the steam generation methods by changing the structure of the HRSGs and add equipment that can provide additional heat to the HRSGs. Because sudden changes in the temperature may affect the material properties, it is necessary to perform evaluations with material analyses in future work. 


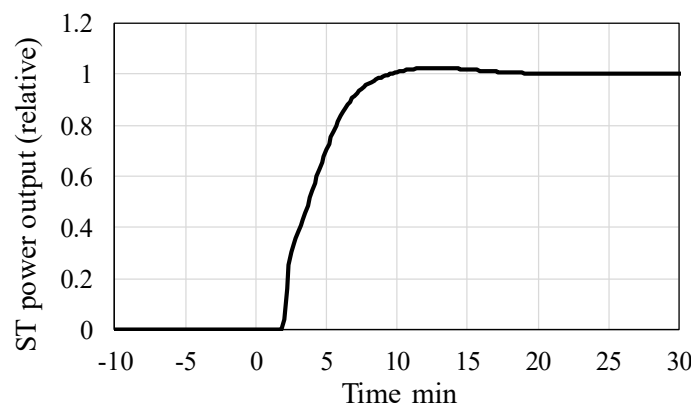

(a) ST power output

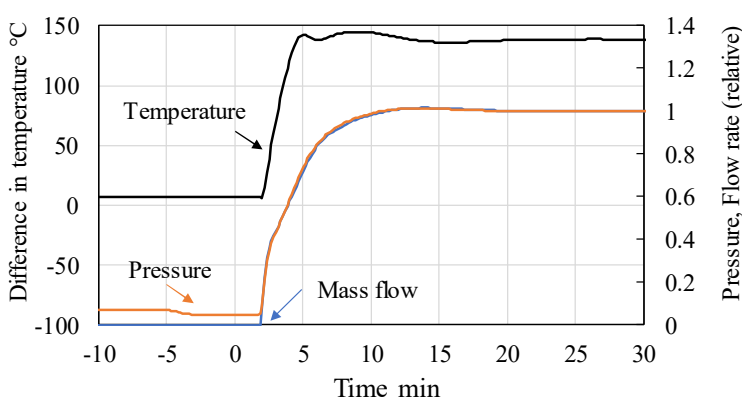

(b) HPT inlet

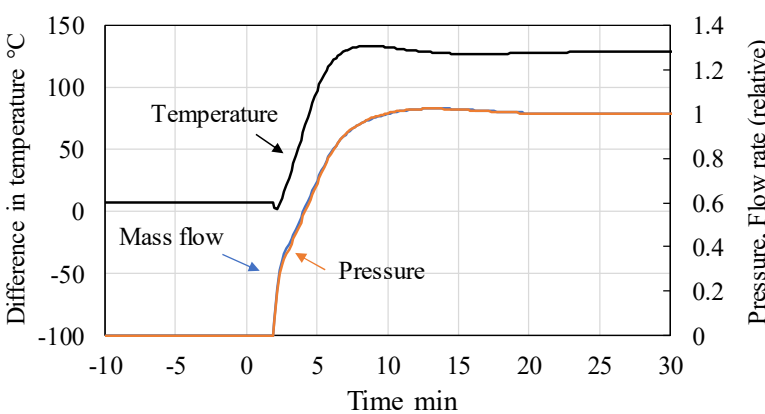

(c) IPT inlet

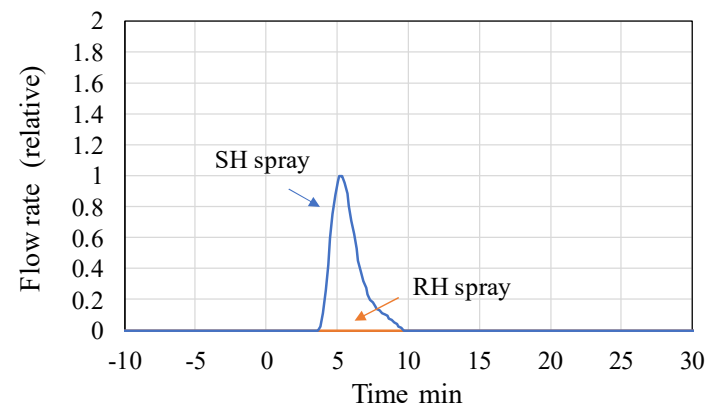

(d) SH and RH spray

Figure 7 Simulation result (normal case)

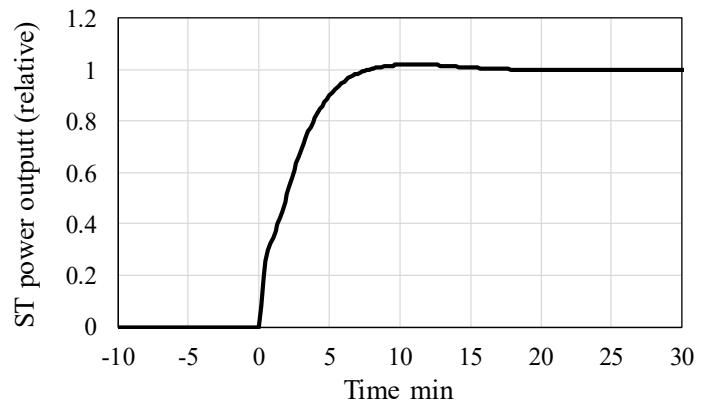

(a) ST power output

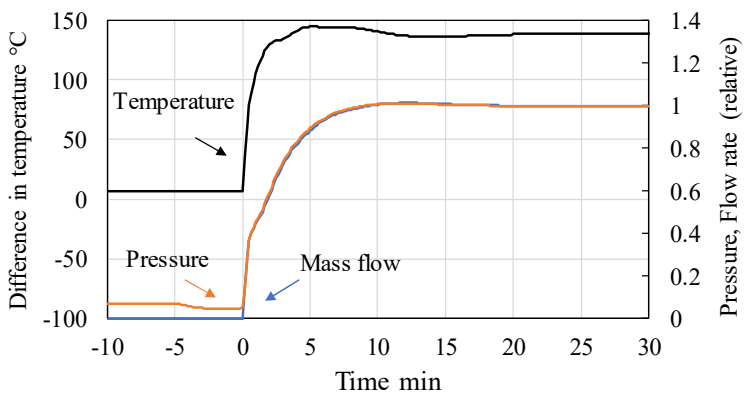

(b) HPT inlet

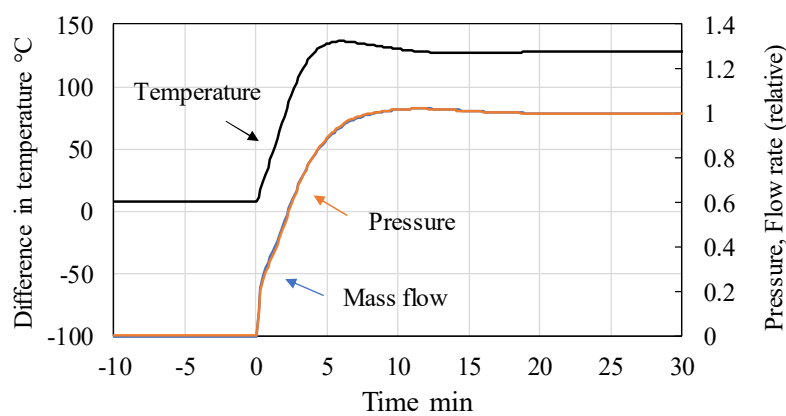

(c) IPT inlet

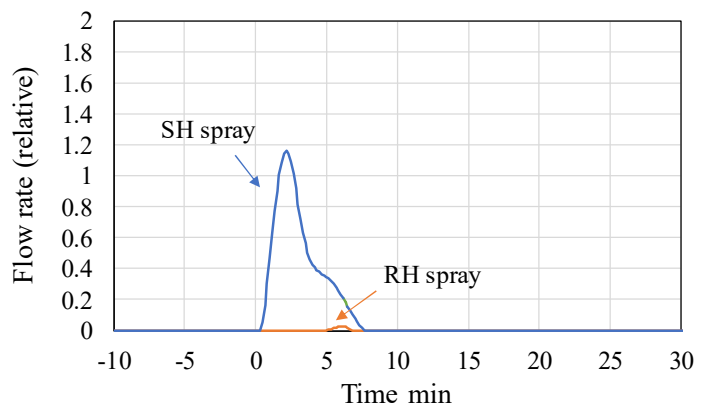

(d) SH and RH spray

Figure 8 Simulation result (with duct firing)

\section{CONCLUSION}

In this study, the performance and dynamic characteristics during the start-up process of an advanced GTCC were simulated to address the challenges in the development of such systems and evaluate the performance capacity in terms of the ST power output. Using the results of the heat and mass balance calculation, a realistic GTCC configuration that can satisfy the target rating and partial load efficiency was established. In addition, a dynamic model based on the obtained configuration was constructed, and a start-up simulation was performed to evaluate the behaviour of the HRSG/ST when using a highly flexible GT. The dynamic simulation results indicated that the target start-up time of the GTCC was not attained even when the current operating constraints were excluded and additional measures may be required to be 
implemented, especially in the steam bottoming system side. Nevertheless, the addition of the duct burner reduced the start-up time to a certain extent. In future work, realistic and more effective solutions may be established using the developed model, by further improving the equipment configuration, using a novel control logic, and evaluating the material properties under actual mechanical constraints.

\section{ACKNOWLEDGMENTS}

This paper is based on results obtained from a project, JPNP16002, commissioned by the New Energy and Industrial Technology Development Organization (NEDO).

\section{References}

Alobaid, F., Mertens, N., Strarkloff, R., Lanz, Thomas., Heinze, C. and Epple, B. (2017). Progress in dynamic simulation of thermal power plants. Progress in Energy and Combustion Science, 59, pp. 79-162.

Alobaid, F. (2018). Start-up improvement of a supplementary-fired large combined-cycle power plant. Journal of Process Control, 64, pp. 71-88.

Caceres, E. I., Montanes, M. R. and Nord, O. L. (2018). Flexibility operation of combined cycle gas turbine power plants with supplementary firing. Journal of Power Technologies, 98(9), pp. 188-197.

Gas turbine world (GTW). (2019). 2019 GTW Handbook. Volume 34.

Government of Japan. (2019). The long-term strategy under the Paris Agreement. https:/unfccc.int/sites/default/files/resource/The\%20Long-term\%20Strategy\%20under\%20the\%20Agreement.pdf

Hermans, M., Bruninx, K. and Delarue, E. (2018). Impact of CCGT start-up flexibility and cycling costs towards renewables integration. IEEE Transaction on Sustainable Energy, 9(3), pp. 1468-1476.

IEA. (2018). Status of power system transformation 2018. https://webstore.iea.org/status-of-power-system-transformation-2018 [Accessed April 9, 2020].

Koda, E. and Takahashi, T. (2002). Development of general-purpose software to analyze the steady state of power generation systems. Energy Conversion and Management, 43(9), pp. 1407-1416.

The Ministry of Economy, Trade and Industry (METI). (2018). The 5th Strategic Energy Plan. https://www.enecho.meti.go.jp/en/category/others/basic_plan/5th/pdf/strategic_energy_plan.pdf

Modelica, https://www.modelica.org/ [Accessed April 9, 2020].

Liese, E. and Zitney, S. E. (2018). Using dynamic simulation to evaluate attemperator operation in a natural gas combined cycle with duct burners in the heat recovery steam generator. Journal of Engineering for Gas Turbines and Power, 140(1). https://doi.org/10.1115/1.4037709

Takahashi, T., Nakao, Y. and Koda, E. (2007). Analysis and evaluation about advanced humid air turbine system. Challenges of Power Engineering and Environment, Springer, Berlin, pp. 341-344.

Takahashi, T., Koda, E. and Nakao, Y. (2011). Development of performance deterioration diagnosis method for gas turbine combined cycle power plants. Journal of Power and Energy Systems, 5(3), pp. 249-262.

Teplov, B.D. and Radin, Y.A. (2019). Improving flexibility and economic efficiency of CCGT units' operation in the conditions of the wholesale electricity market. Thermal Engineering, 66(5), pp. 323-330. https://doi.org/10.1134/S0040601519050094

Thermoflow. (2020) GT PRO. http://www.thermoflow.com/products_gasturbine.html [Accessed April 7, 2020$].$

Watanabe, Y., Takahashi, T. and Nakamoto, M. (2017) Dynamic simulation of startup characteristics for the advanced humid air turbine system. ASME Turbo Expo 2017: Turbomachinery Technical Conference and Exposition, GT201764699.

Watanabe, Y. and Traverso, A. (2019). Dynamic Simulation of steam bottoming system in a combined cycle power plant with Modelica. Proceedings of International Gas Turbine Congress (IGTC) 2019 Tokyo, IGTC-2019-164. 